\title{
Correction to: Multiple Quaternary erosion and infill cycles in overdeepened basins of the northern Alpine foreland
}

\author{
Marius W. Buechi ${ }^{1} \cdot$ Hans Rudolf Graf ${ }^{2} \cdot$ Peter Haldimann $^{3} \cdot$ Sally E. Lowick ${ }^{1} \cdot$ Flavio S. Anselmetti $^{1}$
}

Published online: 27 February 2018

(C) Swiss Geological Society 2018

\section{Correction to: Swiss Journal of Geosciences}

https://doi.org/10.1007/s00015-017-0289-9

In the original version of this article, some corrections had not been implemented. The following changes were necessary:

1. Caption Fig. 1 "glaciated" has been replaced with "glacial".

2. Table 3 Column "Comments", first page: "NIRSL not considered" has been replaced with "IRSL not considered".

The original article has been corrected.

The original article can be found online at https://doi.org/10.1007/ s00015-017-0289-9.

Editorial handling: A.G. Milnes.

Marius W. Buechi

marius.buechi@geo.unibe.ch

1 Institute of Geological Sciences and Oeschger Centre for Climate Change Research, University of Bern, Bern,

Switzerland

2 Dr. von Moos AG, Zurich, Switzerland

3 Dr. Heinrich Jäckli AG, Zurich, Switzerland 